\title{
STYRAX ACUM INATUS (STYRACACEAE), NUEVO REGISTRO PARA LA FLORA ARGENTINA
}

\author{
José L. Rojas \& Héctor A. Keller
}

Instituto de Botánica del Nordeste, UNNE-CONICET, Casilla de Correo 209, 3400 Corrientes, Argentina; kellerhector@hotmail.com (autor corresponsal).

\begin{abstract}
Rojas, J. L. \& H. A. Keller. 2019. Styrax acuminatus (Styracaceae), new record for the Argentinian flora. Darwiniana, nueva serie 7(1): 174-178.

Styrax is a genus of woody plants with about 130 species. In Argentina two species has been recorded. In the present contribution, a third species, Styrax acuminatus, is reported for the first time for the province of Misiones. A description of the species, field pictures, ecological observations, a distribution map, and a key to the species of Styrax in Argentina are provided.
\end{abstract}

Keywords. Flora; Misiones; Styrax; taxonomy.

Resumen. Rojas, J. L. \& H. A. Keller. 2019. Styrax acuminatus (Styracaceae), nuevo registro para la flora argentina. Darwiniana, nueva serie 7(1): 174-178.

El género Styrax incluye cerca de 130 especies leñosas. Para la Argentina han sido registradas dos especies. En la presente contribución una tercera especie, Styrax acuminatus, es citada por primera vez para la provincia de Misiones. Se provee una descripción de la especie, fotografías de campo, observaciones ecológicas, un mapa de distribución y una clave para distinguir a las especies de Styrax presentes en la Argentina.

Palabras clave. Flora; Misiones; Styrax; taxonomía.

\section{INTRODUCCIÓN}

La familia Styracaceae comprende árboles o arbustos perennifolios o caducifolios con hojas alternas, simples y pecioladas; indumento de tricomas estrellados o peltados; inflorescencias en cimas axilares o panículas, o a veces de una o dos flores, generalmente bracteoladas; flores bisexuales o pistiladas, actinomorfas (Fritsch, 2004).

La familia contiene 11 géneros y aproximadamente 160 especies; se distribuye en las zonas templado-cálidas a tropicales de América, en las áreas que bordean la cuenca del Pacífico occidental y en la región mediterránea (Fritsch et al., 2001).
El género Styrax es, por mucho, el más numeroso de la familia, con alrededor de 130 especies, que corresponde al $80 \%$ del número total de especies de la familia (Pauletti et al., 2006). Se diferencia de los otros diez géneros de Styracaceae por presentar sinfiandro que se adhiere a los pétalos y óvulos con dos tegumentos (Fritsch, 1999). Es un género con amplia distribución, principalmente en regiones tropicales y subtropicales. Ocurre en Asia oriental, Nueva Guinea, la región del Mediterráneo oriental, el Caribe, América del Sur, América Central y América del Norte (Gonsoulin, 1974).

En la Argentina, hasta el presente, se encuentran citadas sólo dos especies para la familia: Styrax 
subargenteus Sleumer y S. leprosus Hook. \& Arn. (Fritsch, 2008). La primera con una distribución en la Selva Tucumano-Boliviana y la segunda en la Selva Misionera y, fuera de ella, en el norte de la provincia de Corrientes (Tortorelli \& Castigloni, 1948). En el presente trabajo se cita por primera vez a Styrax acuminatus Pohl para la Argentina y se presenta una clave para diferenciar las tres especies nativas del género presentes en este país.

\section{MATERIALES Y MÉTODOS}

El material analizado se recolectó en la Reserva Forestal Privada San Jorge, en el noroeste del departamento de Iguazú, en la provincia de Misiones, y se depositó en el herbario CTES (Thiers, 2018). Se examinaron las imágenes digitales de material tipo disponible en Jstor Plant Science (https://plants. jstor.org), el herbario virtual REFLORA, de Brasil (http://www.reflora.jbrj.gov.br) y del herbario W (https://herbarium.univie.ac.at).

Para obtener una estimación preliminar de la densidad de adultos y de regeneración natural de una de las poblaciones de $S$. acuminatus halladas en la Reserva San Jorge se utilizó el método de transectos variables propuesto por Montadesco \& Fredericksen (2000). En total se midieron seis parcelas de $100 \mathrm{~m}^{2}$ para árboles adultos (individuos con más de $10 \mathrm{~cm}$ de diámetro a $1,3 \mathrm{~m}$ de altura) y seis parcelas de $10 \mathrm{~m}^{2}$ para la regeneración (individuos con menos de $10 \mathrm{~cm}$ de diámetro a 1,3 $\mathrm{m}$ de altura).

\section{RESULTADOS}

Styrax acuminatus Pohl, Pl. Bras. Icon. Descr. 2:58, tab. 138, 1831. Strigilia acuminata (Pohl) Miers, Ann. Mag. Nat. Hist., ser. 3, 3: 282. 1859. TIPO: Brasil. "Hábitat inter frutices circa Marambaia Capitaniae Rio de Janeiro", Schott s.n. (no localizado). Fig. 1.

Styrax alutaceus Seub., Fl. Bras. 7: 190. 1868. Styrax acuminatus var. alutaceus (Seub.) Perkins, Pflanzenr. 30 (IV 241): 45, 1907. TIPO: Brasil. "Crescit in Brasilia austro-orintali", Sello 206 (isotipo K cb 000644416!).
Árboles hasta $15 \mathrm{~m}$ de altura; ramas con tomento cinéreo formado por escamas y tricomas estrellados. Hojas con peciolo de 6,5-10 mm; lamina ovada, ovado-oblonga o elíptico-lanceolada, de 6-12 x 2,5-3,6 cm, base aguda o cuneada, ápice agudo a acuminado, subcartácea, discolora, cara adaxial escamosa a glabrescente, cara abaxial cinérea, con pelos estrellados densos; nervios con tricomas castaños o amarillentos de 0,2-0,30 mm de diám., densamente distribuidos en las nervaduras y esparcidos en la hoja,. Racimos axilares de 1,5-3,5 $\mathrm{cm}$, con 1-5 flores, raquis castaño. Flores de 1-1,7 cm, pedicelo de 3,5-5 $\mathrm{mm}$; bractéolas caducas situadas en la porción media del pedicelo; cáliz ca. $5 \times 4 \mathrm{~mm}$, con el margen truncado, castaño-amarillento con tricomas amarillos y castaños esparcidos sobre un indumento cinéreo de escamas y pelos estrellados; tubo de la corola ca. 1,5 mm, lóbulos reflexos de $11-13,5$ x 2,5 mm; estambres 10, de 8,5-9,5 mm; filamentos pubescentes, libres y un tanto aplanados unos $2 \mathrm{~mm}$, concrescentes unos $3 \mathrm{~mm}$; anteras ca. 6 $\mathrm{mm}$, con pelos estrellados en el margen; ovario de 1,5 mm, multiovulado. Drupa elipsoide u obovoide, de 1,5-1,7 x 1-1,1 cm, con el cáliz persistente.

Iconografía. Flaster (1973: 17).

Nombres vulgares: En el sur de Brasil es conocida como "Pau de remo", "Jaguatinga" y "Pororoca", en São Paulo como "Estoraque do campo", "Estoraque do mato" y "Estoraque liso" (Capistrano, 2012).

Distribución y Hábitat. En Brasil ha sido registrada para los estados de Santa Catarina, Paraná, Rio Grande do Sul, São Paulo y Rio de Janeiro (Fritsch, 2015). También ocurre en Uruguay (Montevideo) y Paraguay (Amambay y Canindeyú) (Fritsch, 2008). En la Argentina la especie fue hallada en interior de la selva, en la Reserva Privada San Jorge, al noroeste de la provincia de Misiones en el departamento de Iguazú (Fig. 2).

En Brasil crece en la selva umbrófila y en la restinga alta (Capistrano, 2012). En Santa Catarina, se la menciona como una especie higrófita y esciófita, muy rara, que ocurre preferentemente en los bosques de la costa tropical atlántica, también en bosques de Araucaria angustifolia (Bertol.) Kuntze ("araucaria") del planalto, situados en suelos húmedos (Flaster, 1973). 


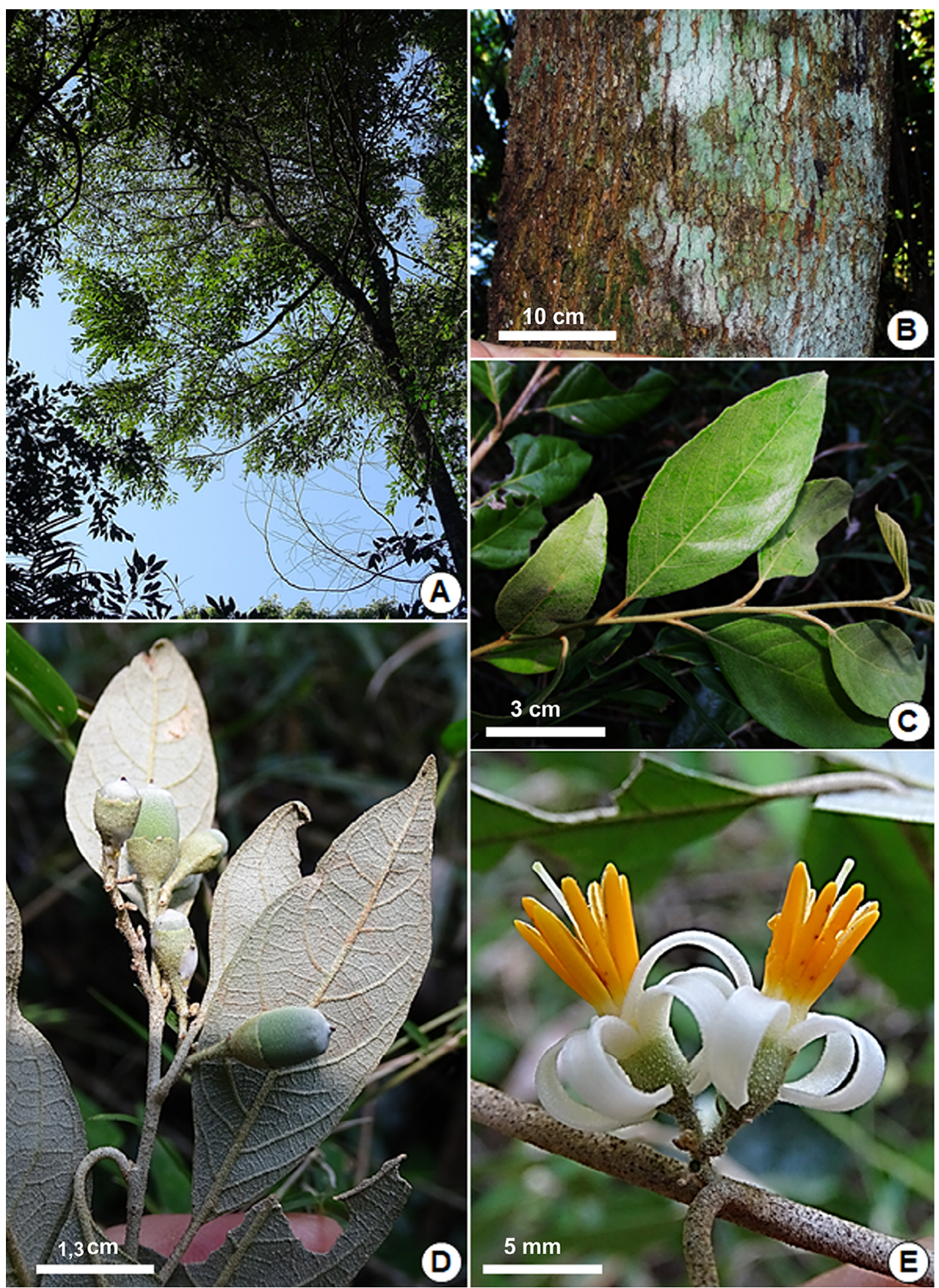

Fig. 1. Styrax acuminatus. A, copa. B, corteza. C, rama con hojas (vista del epifilo). D, rama con hojas (vista del hipofilo) y frutos. E, flores. A-D, de Keller \& Rojas 13488 (CTES); E de Keller \& Rojas 13492 (CTES). Fotografías de H. A. Keller. Figura en color en la versión en línea http://www.ojs.darwin.edu.ar/index.php/darwiniana/article/view/818/1155 
En Misiones se comporta como una especie pionera durable, conformando poblaciones densas de fustales en claros amplios. Los ejemplares de mayor tamaño se encuentran formando parte de la comunidad climáxica.

El muestreo en poblaciones de la Reserva San Jorge permitió estimar una densidad de ejemplares adultos de alrededor de 300 ejemplares/ha. Por su parte, la regeneración natural alcanza valores de más de 4800 brinzales-latizales/ha. y 500 fustales/ ha. Ello sugiere una población en equilibrio en la cual el número de individuos de las clases diamétricas de menor tamaño cuentan con abundante "stock" de ejemplares para posibilitar un reclutamiento adecuado a clases de tamaño mayores (Louman et al., 2001).

\section{Material representativo examinado}

ARGENTINA. Misiones. Depto. Iguazú, Reserva San Jorge, $25^{\circ} 49^{\prime} 58,5^{\prime}$ ' S $54^{\circ} 17^{\prime} 48,4^{\prime \prime} \mathrm{W}$, 22-XI-2016, fl, fr, Keller \& Rojas 13488 (CTES), Ídem., $25^{\circ} 49^{\prime} 56,5^{\prime}$ S - 54 ${ }^{\circ} 17^{\prime} 51,7^{\prime}$ ' W, 22-XI2016, fl, Keller \& Rojas 13492 (CTES).

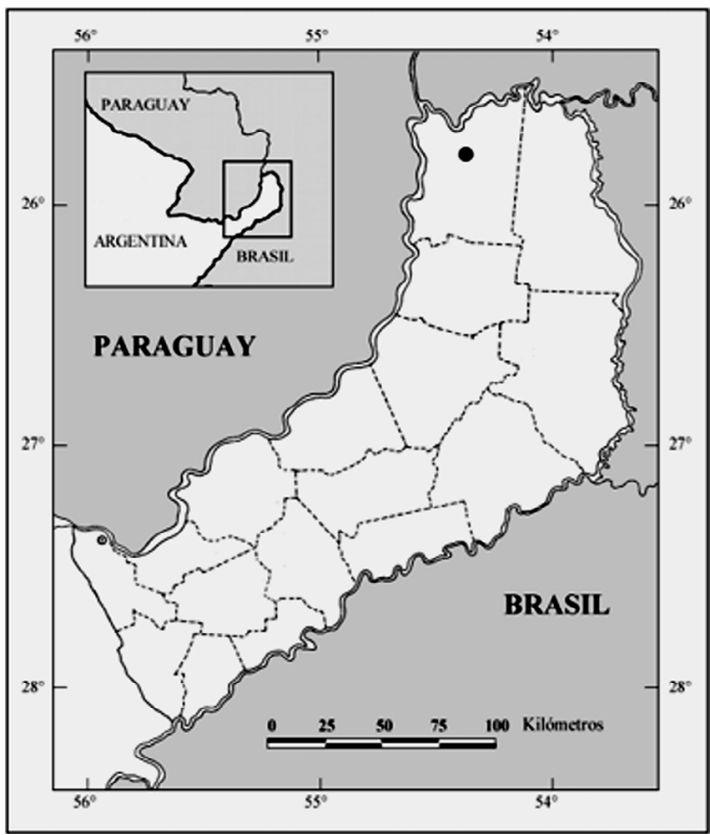

Fig. 2. Sitio de colección de Styrax acuminatus en la provincia de Misiones (círculo negro).

\section{Clave para diferenciar las especies de Styrax en la Argentina}

1. Indumento de escamas peltadas (plantas lepidotas)

S. leprosus

1. Indumento de pelos estrellados

S. subargenteus

2 (1). Pedicelos 5-8 mm, cáliz 3-4,5 mm alt., fruto ca. $13 \mathrm{~mm}$ long x $7 \mathrm{~mm}$ diám

2. Pedicelos 3,5-5 mm, cáliz 4-5 mm alt., fruto 15-17 mm long x 10-11 mm diám S. acuminatus

\section{AGRADECIMIENTOS}

A Gustavo Aparicio (Fundación Hábitat y Desarrollo) y Liliana Rivero (Arauco S.A.) por posibilitar las campañas de recolección en Misiones.

\section{BIBLIOGRAFIA}

Capistrano, T. R. 2012. Flora fanerogâmica do estado de São Paulo: Dissertação (Mestrado). Instituto de Botânica da Secretaria de Estado do Meio Ambiente. São Paulo, 73pp.

Flaster, B. 1973. Estiracáceas. En R. Reitz (ed.), Fl. Il. Catarinense part I, fasc. ESTI: 3.23.
Fritsch, P. W. 1999. Phylogeny of Styrax based on Morphological Characters, with implications for Biogeography and Infrageneric Classification. Systematic Botany 24(3): 356-378.

Fritsch, P. W. 2004. New species and taxonomic changes in Styrax (Styracaceae) from South America. Novon 14(1): 43-57.

Fritsch, P. W. 2008. Styracaceae. En F. O. Zuloaga, O. Morrone, M. J. Belgrano, C. Marticorena \& E. Marchesi (eds.), Catálogo de las plantas vasculares del Cono Sur, Monographs in Systematic Botany from the Missouri Botanical Garden 107(3): 3064-3067.

Fritsch, P. W. 2015. Styracaceae, en Lista de Espécies da Flora do Brasil. Jardim Botânico do Rio de Janeiro. Disponible en: http://floradobrasil.jbrj.gov.br

Fritsch, P. W.; C. M. Morton, T. Chen \& C. Meldrum. 2001. Phylogeny and Biogeography of the Styracaceae. International Journal of Plant Sciences 1626(162): 95-116. 
Gonsoulin, G. J. 1974. A revision of Styrax (Styracaceae) in North America, Central America, and the Caribbean. Sida 5(4): 191-258.

Louman, B.; D. Quirós \& M. Nilsson. 2001. Silvicultura de bosques latifoliados húmedos con énfasis en América Central. Turrialba: CATIE.

Montadesco, B. \& T. Fredericks. 2000. Manual de métodos básicos de muestreo y análisis en ecología vegetal. Santa Cruz: BOLFOR.
Pauletti, P. M.; H. L. Teles, D. H. S. Silva, Â. R. Araújo, \& V. S. Bolzani. 2006. The Styracaceae. Brazilian Journal of Pharmacognosy 16(4): 576-590.

Thiers, B. [permanentemente actualizado, consulta 2018] Index Herbariorum: a global directory of public herbaria and associated staff. New York Botanical Garden's Virtual Herbarium, http://sweetgum.nybg.org/ih

Tortorelli, L. A. \& J. A. Castigloni. 1948. Estudio dendrológico de las Estiracáceas argentinas. Lilloa 16: 125-139. 